ISSN 0103-9954

\title{
CARACTERIZAÇÃO DO SETOR FLORESTAL: UMA ABORDAGEM COMPARATIVA COM OUTROS SETORES DA ECONOMIA
}

\section{CHARACTERIZATION OF THE FOREST SECTION: A COMPARATIVE EVALUATION WITH OTHER ECONOMY SECTORS}

\author{
Rosa Maria Miranda Armond Carvalho ${ }^{1}$ Thelma Shirlen Soares ${ }^{1}$ Sebastião Renato Valverde ${ }^{2}$
}

\section{RESUMO}

Neste trabalho, buscou-se caracterizar e dimensionar o setor florestal brasileiro comparando-o a outros setores da economia nacional. Adicionalmente, apresentam-se os principais segmentos evidenciando as principais características do segmento privado desse setor.

Palavras-chave: economia florestal; setor florestal.

\section{ABSTRACT}

This work attenpted to characterize and measure the Brazilian forest sector comparing it to other sectors of the national economy. Additionally, there is presented its main segments evidencing the main characteristics of the private segment of this sector.

Key-words: forest economy; forest sector.

\section{INTRODUÇÃO}

O Brasil possui uma área florestal significativa, seja de nativas ou plantadas. A parte de nativas, susceptível de manejo, é de aproximadamente 450 milhões de hectares, compreendida pelas áreas de Unidades de Conservação da categoria de uso sustentável sob o poder público como as Reservas Extrativistas, as Reservas de Desenvolvimento Sustentável e as Florestas Nacionais, Estaduais e Municipais, e sob a iniciativa privada, as Reserva Legais das Propriedades Rurais e as de Produção das indústrias.

O Brasil possui uma das maiores áreas de florestas plantadas no mundo, sobretudo, as de eucalipto. Algumas estatísticas apontam a existência de quase 5 milhões de hectares.

Para melhor conhecimento do setor florestal e de sua importância para a economia como um todo, vale caracterizá-lo em seus aspectos técnicos, sociais e econômicos. Nesse contexto, elaborou-se a presente revisão na qual se procura abordar, de forma sucinta, os principais aspectos relacionados ao setor florestal brasileiro.

\section{REVISÃO BIBLIOGRÁFICA}

\section{O setor florestal brasileiro}

O setor florestal pode ser conceituado como parte da sociedade relacionada ao uso dos recursos silvestres ou florestal. Ele se relaciona especialmente ao uso da fauna (exceto peixe) e dos recursos da flora, em particular, das florestas naturais ou plantadas.

Segundo Hummel e Minette (1990), quase 50\% das florestas tropicais úmidas naturais existentes estão na América tropical e, deste total, mais de 80\% (50\% no Brasil + 30\% em outros países da América do Sul) se encontram na região amazônica. Da área pertencente ao território brasileiro, o estado do Amazonas é o que detém o maior percentual.

Antes de passar efetivamente ao exame da participação do setor florestal no contexto da economia nacional, considera-se oportuno e necessário, retratar o volume dos recursos florestais brasileiros.

As principais Regiões Fisiográficas do Brasil são: Floresta Amazônica, Caatinga, Cerrado, Mata Atlântica, Pantanal Mato-Grossense, outras formações (Campos do Sul (Pampas), Mata das Araucárias (Região dos Pinheirais), Ecossistemas Costeiros e Insulares) (Brasil, 2003). Já as florestas plantadas brasileiras ocupam uma área de 4,8 milhões de hectares, Desse total, cerca de 3 milhões de hectares correspondem a plantações de Eucalipto, e 1,8 milhões de hectares a plantações de pinus.

1. Doutoranda em Ciência Florestal, Universidade Federal de Viçosa, CEP 36571-000, Viçosa (MG).

2. Professor do Departamento de Engenharia Florestal, Universidade Federal de Viçosa, CEP 36571-000, Viçosa (MG).

Recebido para publicação em 17/12/2003 e aceito em 8/03/2005. 
A cobertura florestal do território brasileiro, associada às excelentes condições edafo-climáticas para a silvicultura, confere ao País grandes vantagens comparativas para a atividade florestal. Existe um consenso entre especialistas, tais como Garlip (2001), Assis (2003), Valverde et al. (2003), Silva (2003), entre outros quanto à relevância social, econômica e ambiental do setor florestal e sua importância para o desenvolvimento do Brasil.

Alguns macroindicadores dessa importância se baseiam na formação do PIB, na geração de divisas e na contribuição para a melhoria da qualidade de vida da sociedade.

De fato, o setor florestal brasileiro contribui com cerca de 5\% na formação do PIB Nacional e com 8\% das exportações; gera 1,6 milhão de empregos diretos, 5,6 milhões de empregos indiretos e uma receita anual de R $\$ 20$ bilhões; recolhe anualmente $\mathrm{R} \$ 3$ bilhões de impostos; conserva uma enorme diversidade biológica (com 6,4 milhões de hectares de florestas plantadas, sendo 4,8 milhões com florestas de produção de Pinus e Eucaliptos; mantém 2,6 milhões de hectares de florestas nativas) (IPEF, 2003).

No que diz respeito aos aspectos sociais, o setor florestal é capaz de absorver mão-de-obra numerosa, colaborando assim para uma melhor distribuição de renda para a população. Vale lembrar que a exploração racional das florestas, com base no manejo sustentável, também propicia a melhoria das condições de transporte, acesso e comunicação de determinada localidade.

Quanto ao meio ambiente, as influências florestais podem ser divididas em três grupos: as influências diretas (efeito mecânico), influências indiretas (efeito físico-químico) e as influências psicofisiológicas (as que atuam diretamente sobre o homem).

Segundo Polzl et al. (2003), o segmento madeireiro do setor florestal organiza-se em duas direções uma longitudinal e outra transversal. Do ponto de vista transversal, distinguem-se os processos sucessivos de transformação que levam a madeira de um estado bruto a um estado considerado como final. Essa sucessão compreende as seguintes atividades: silvicultura, colheita florestal, primeira transformação, segunda transformação, terceira transformação, consumidor final.

Ainda segundo os autores, em função do plano longitudinal, pode-se segmentar a cadeia produtiva da madeira em três grandes cadeias, em função das distinções na utilização da madeira bruta. São elas: energia, processamento mecânico e madeira industrial, conforme o demonstrado na Figura 1.

Cabe ressaltar que o setor florestal não é caracterizado apenas pelos produtos madeireiros, mas também pelos produtos florestais não-madeireiros os quais, segundo a FAO (1998), são representados por produtos para o consumo humano (alimentos, bebidas, plantas medicinais e extratos, como por exemplo, frutas, bagas, nozes, mel, fungos, entre outros); farelos e forragem (campos para pastagem); e outros produtos não-madeireiros (tais como cortiça, resinas, taninos, extratos industriais, plantas ornamentais, musgos, samambaias, óleos essenciais, etc.).

Frise-se que por causa da extensão do setor florestal, enfocar-se-á aqui apenas o segmento madeireiro.

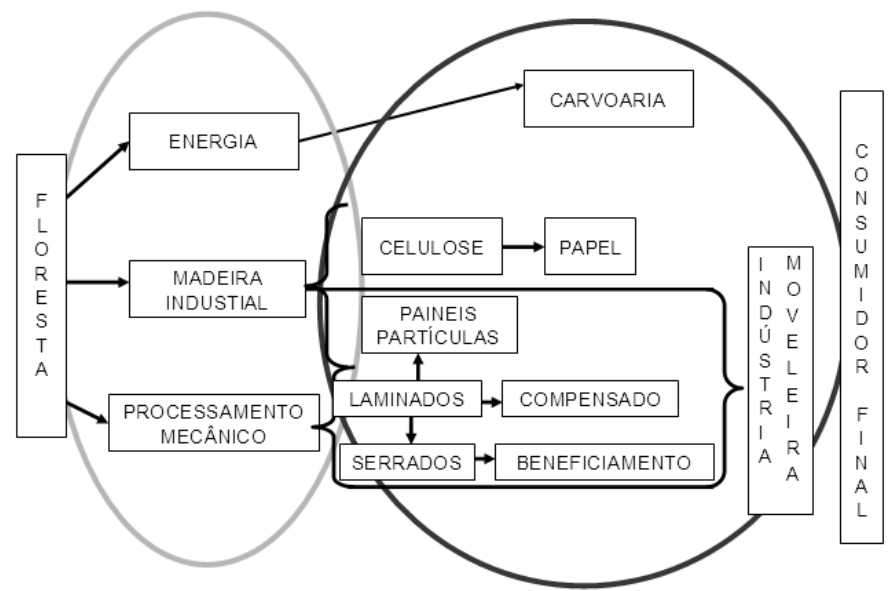

FIGURA 1: Fluxograma geral da cadeia produtiva da madeira (Adaptado de Polzl et al. 2003).

FIGURE 1: General flowchart of the wood productive chain (Adapted from Polzl et al. 2003). 
Ao se buscar o contraste do setor florestal com os demais setores da economia brasileira, vale ressaltar que as atividades florestais apresentam peculiaridades que as diferencia.

Segundo Rezende et al. (1996), entre essas características se destacam: o longo prazo, o alto custo econômico para a sua implantação, o problema da escolha da taxa de juros a ser utilizada, a necessidade e, ao mesmo tempo, a dificuldade de obtenção de informações corretas, as várias opções de uso da madeira, a presença de externalidades e de bens públicos, dentre os muitos benefícios produzidos.

Ao se examinar o valor do Produto Interno Bruto brasileiro, em 1999, e a participação de cada setor na sua formação, constata-se que o setor florestal ocupou o sétimo lugar e contribuiu com $2,26 \%$, conforme a Tabela 1 .

TABELA 1: Valor do Produto Interno Bruto $(\mathrm{R} \$ 1.000,00)$ brasileiro em 1999.

TABLE 1: Brazilian Gross Domestic Product Values (R\$1.000,00) in 1999.

\begin{tabular}{l|c|c}
\hline \multicolumn{1}{c}{ Setor } & PIB $(\mathrm{R} \$)$ & $(\%)$ \\
\hline Diversos & 4.052 .515 & 0,41 \\
Fármaco & 9.251 .158 & 0,94 \\
Eletroeletrônico & 12.226 .045 & 1,24 \\
Veículos & 18.346 .223 & 1,87 \\
Maquinário & 18.651 .422 & 1,90 \\
Plástico & 19.047 .634 & 1,94 \\
Florestal & 22.200 .740 & 2,26 \\
Mineração & 22.878 .777 & 2,33 \\
Metalsiderúrgico & 23.392 .671 & 2,38 \\
Alimentícios & 44.890 .163 & 4,57 \\
Petroquímico & 52.477 .269 & 5,34 \\
Agricultura & 77.677 .795 & 7,91 \\
Serviços & 657.541 .839 & 66,92 \\
\hline Total & 982.636 .250 & 100,00 \\
\hline
\end{tabular}

Fonte: Adaptado de Valverde et al. (2003).

De acordo com Valverde et al. (2003), no que diz respeito às importações, o setor florestal brasileiro apresentou, em 1999, a quarta maior de todas as importações, sendo superada apenas pelos setores de alimentícios, serviços e metalsiderúrgico.

Pelo lado das exportações, o setor de alimentícios foi o que apresentou as maiores exportações, $21,5 \%$ do total exportado, em 1999 enquanto o florestal contribuiu com $8,34 \%$.

Os setores eletroeletrônico e petroquímico foram os que apresentaram os maiores déficits na balança comercial brasileira, seguidos dos setores de serviços e maquinário. O setor florestal foi um dos que apresentaram superávit na balança comercial, com o terceiro melhor resultado (Figura 2).

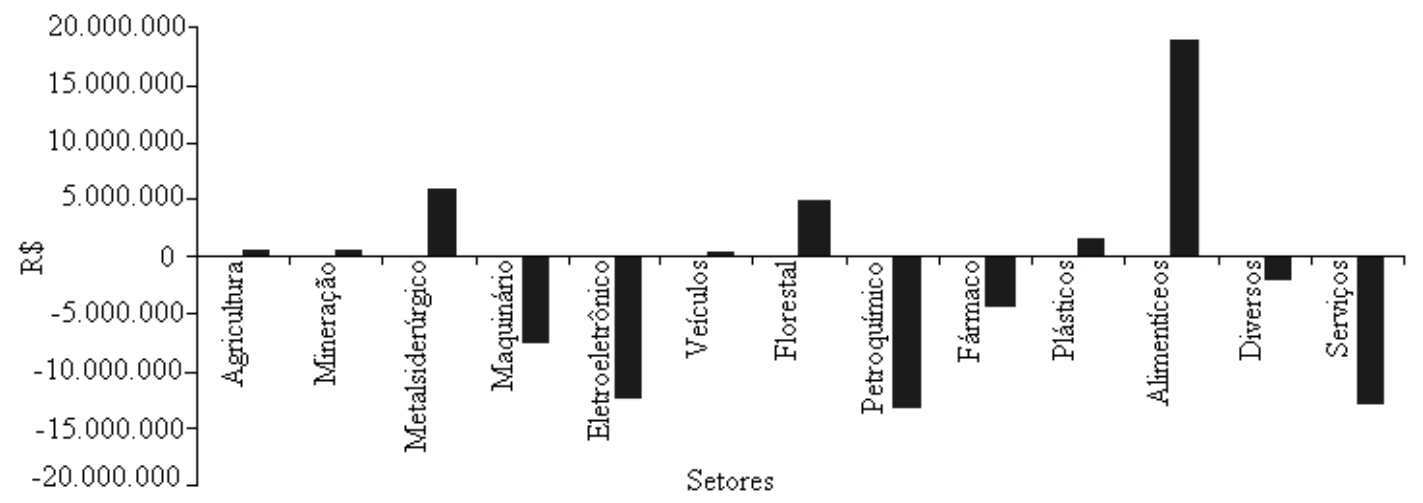

FIGURA 2: Saldo da balança comercial brasileira, por setor, no ano de 1999. (Adaptado de Valverde et al., 2003).

FIGURE 2: Brazilian trade balance, by sector, in 1999 (Adapted from Valverde et al., 2003). 
Com relação ao pagamento de salários, observa-se, em 1999, que o setor florestal foi o quarto maior a contribuir com a renda salarial dos trabalhadores brasileiros (Tabela 2).

TABELA 2: Remuneração salarial $(\mathrm{R} \$ 1.000,00)$ dos trabalhadores brasileiros por setor econômico, no ano de 1999.

TABLE 2: Wages $(\mathrm{R} \$ 1.000,00)$ of the Brazilian workers by economic sector, in 1999.

\begin{tabular}{l|c|c}
\hline \multicolumn{1}{c}{ Setor } & Remuneração & $(\%)$ \\
\hline Agricultura & 10.113 .583 & 2,75 \\
Mineração & 5.012 .043 & 1,36 \\
Metalsiderúrgico & 5.766 .555 & 1,57 \\
Maquinário & 5.247 .589 & 1,43 \\
Eletroeletrônico & 2.696 .462 & 0,73 \\
Veículos & 4.793 .863 & 1,30 \\
Florestal & 7.521 .666 & 2,04 \\
Petroquímico & 4.932 .198 & 1,34 \\
Fármaco & 1.822 .349 & 0,50 \\
Plástico & 6.392 .644 & 1,74 \\
Alimentícios & 8.316 .490 & 2,26 \\
Diversos & 1.187 .338 & 0,32 \\
Serviços & 304.119 .377 & 82,66 \\
\hline Total & 367.922 .157 & 100,00
\end{tabular}

Fonte: Adaptado de Valverde et al. (2003).

Segundo a SBS (2003a), a cada US\$ 1 milhão investidos no setor de base florestal, são gerados 160 empregos, enquanto no setor automotivo, são 85 e na construção civil, 111.

Vale ressaltar que o setor florestal apresenta uma vantagem, em relação aos demais setores, excetuando-se agricultura e alimentícios, que é a de remunerar tanto os trabalhadores urbanos quanto os rurais (Valverde, 2000).

Assis (2003) faz uma proveitosa comparação entre vários aspectos relativos aos empreendimentos agrícolas e florestais mineiros (Tabela 3). A situação apurada pelo autor não se dá, de maneira geral, de forma diferenciada no restante do País.

Pode-se concluir que, apesar do desenvolvimento econômico do Brasil com base no desenvolvimento da atividade florestal ser uma alternativa de grande viabilidade, pois este se tem apresentado, através das últimas décadas, como instrumento impulsionador do desenvolvimento, o setor florestal (quando comparado a outros setores da economia) ainda é tratado de forma inadequada e injusta.

Fato esse que pode ser comprovado por meio dos muitos entraves enfrentados pelo setor, tais como, a excessiva tributação, entraves burocráticos, taxas de juros incompatíveis, a falta de recursos para investimentos, a legislação equivocada, entre outras. Tal cenário impede o aproveitamento pleno das vantagens comparativas inerentes às atividades do setor implicando em limitação da competitividade.

Nesse contexto, destaca-se a necessidade de ações coordenadas dos diferentes atores sociais envolvidos, tendo em vista a construção de um novo cenário que propicie condições do pleno desenvolvimento do setor. 
TABELA 3: Comparação de aspectos relativos aos empreendimentos agrícolas e florestais no estado de Minas Gerais.

TABLE 3: Comparison of aspects related to the agricultural and forest enterprises in state of Minas Gerais, Brazil.

\begin{tabular}{|c|c|c|}
\hline Item & Empreendimento agrícola & Empreendimento florestal \\
\hline $\begin{array}{l}\text { Crédito para } \\
\text { implantação }\end{array}$ & $\begin{array}{l}\text { - Diversas instituições } \\
\text { - Recurso próximo da demanda } \\
\text { - Juros baixos } \\
\text { - Refinanciamento na hipótese de insucesso } \\
\text { - Garantias compatíveis } \\
\text { - Processo simples } \\
\text { - Existe seguro }\end{array}$ & $\begin{array}{l}\text { - Apenas junto ao BDMG } \\
\text { Recursos irrisórios } \\
\text { - Juros altos } \\
\text { - Sem refinanciamento na hipótese de } \\
\text { insucesso } \\
\text { - Garantias incompatíveis } \\
\text { - Processo complexo } \\
\text { - Não existe seguro }\end{array}$ \\
\hline $\begin{array}{l}\text { Crédito para } \\
\text { colheita e } \\
\text { beneficiamento }\end{array}$ & - Existe & - Não existe \\
\hline $\begin{array}{l}\text { Isenção de } \\
\text { impostos } \\
\end{array}$ & - Existe & - Não existe \\
\hline $\begin{array}{l}\text { Colheita e } \\
\text { comercialização }\end{array}$ & $\begin{array}{l}\text { - Colheita livre, a crédito do empreendedor } \\
\text { - Exigência apenas de Nota Fiscal, em muitos } \\
\text { casos livre de trânsito }\end{array}$ & $\begin{array}{l}\text { - Necessário inventário, plano de corte, } \\
\text { vistorias, prazos impostos por portarias e } \\
\text { plantas com referência geodésica } \\
\text { - Com Nota Fiscal } \\
\text { - GCA } \\
\text { - Selo, prestação de contas, registros } \\
\text { diversos } \\
\text { e contrato escrito }\end{array}$ \\
\hline $\begin{array}{l}\text { Impactos } \\
\text { ambientais }\end{array}$ & $\begin{array}{l}\text { - Até } 3 \text { intervenções por ano para plantio } \\
\text { - Até } 3 \text { intervenções por ano para tratos } \\
\text { culturais } \\
\text { - Até } 3 \text { intervenções por ano para colheita } \\
\text { - Maior uso de pesticidas e adubos } \\
\text { - Menor proteção do solo contra erosão } \\
\text { - Menor seqüestro de gás carbônico } \\
\text { - Pequena reciclagem de nutrientes }\end{array}$ & $\begin{array}{l}\text { - Uma intervenção a cada } 21 \text { anos para o } \\
\text { plantio } \\
\text { - } 3 \text { intervenções a cada } 7 \text { anos para tratos } \\
\text { culturais } \\
\text { - Uma intervenção a cada } 7 \text { anos para } \\
\text { colheita } \\
\text { - Menor uso de pesticidas e adubos } \\
\text { - Maior proteção do solo contra erosão } \\
\text { - Grande seqüestro de gás carbônico } \\
\text { - Grande reciclagem de nutrientes } \\
\end{array}$ \\
\hline Risco da atividade & - Alto & - Alto \\
\hline Período de risco & - Curto & - Longo \\
\hline
\end{tabular}

Fonte: Assis (2003).

\section{Caracterização do setor florestal privado}

O setor florestal (empresarial) brasileiro é marcado por sua amplitude o que pode ser avaliado pelo consumo de madeira industrial em toras pelas diferentes atividades (Tabela 4).

TABELA 4: Consumo de madeira industrial em toras - Brasil $/ 2000\left(1.000 \mathrm{~m}^{3}\right)$.

TABLE 4: Log consumption - Brazil/2000 $\left(1.000 \mathrm{~m}^{3}\right)$.

\begin{tabular}{lccc}
\hline Produto & Nativas & Plantadas & Total \\
\hline Celulose e Papel & - & 32.000 & 32.000 \\
Carvão Vegetal & 11.800 & 33.400 & 45.200 \\
Lenha Industrial & 16.000 & 13.000 & 29.000 \\
Serrados & 34.000 & 15.100 & 49.100 \\
Lâminas e Compensados & 2.050 & 3.960 & 6.010 \\
Painéis Reconstituídos* & - & 5.000 & 5.000 \\
\hline Total & 63.850 & 102.460 & 166.310 \\
\hline
\end{tabular}

Em que: * = Incluem aglomerados, chapas de fibra e MDF; Fonte: ABIPA (2003). 
Nesse estudo, será abordada sua primeira transformação industrial que é composta basicamente por três cadeias produtivas ou segmentos: segmento da madeira industrial (subsegmentos: celulose e papel, painéis de madeira reconstituída), segmento do processamento mecânico (serrados e compensados) e segmento de madeira para energia (lenha e carvão).

\section{Segmento da madeira industrial}

\section{Papel e celulose}

O setor produtivo brasileiro de papel e celulose contribui de forma relevante para o desenvolvimento do Brasil. A cadeia produtiva do setor abrange as etapas de produção de madeira, energia, celulose e papel, conversão em artefatos de papel e papelão, reciclagem de papel, produção gráfica e editorial, além de atividades de comércio, distribuição e transporte.

Vale ressaltar que o produto da indústria de celulose (a pasta de celulose) é usada sobretudo na indústria de papel, em geral com instalações relativamente grandes suprindo tanto o mercado interno como o externo.

Segundo a BRACELPA (2003) o setor utiliza exclusivamente madeira de florestas plantadas (eucalipto e pinus), possui 220 empresas localizadas em 450 municípios de 16 estados, nas cinco regiões brasileiras, gera 100 mil empregos diretos nas indústrias e florestas, possui 1,4 milhão de hectares de florestas plantadas (Eucalipto: 1 milhão e Pinus: 400 mil), bem como uma área de florestas nativas preservadas e cultivadas de 1,5 milhão de hectares.

Ainda segundo a entidade, em 2002, a Produção brasileira de celulose foi de 8.011.481 toneladas e a de papel 7.661.184 toneladas. Nesse mesmo ano, o setor exportou US\$ 2,1 bilhões, gerando saldo comercial de US\$ 1,5 bilhão, pagou R $\$ 1,7$ bilhão em impostos, produziu 8 milhões de toneladas de celulose ( $7^{\circ}$ do mundo) 37,7 milhões de toneladas de papel (11을 do mundo) e reciclou 3 milhões de toneladas de papel.

Diante de tais números, pode-se afirmar que a indústria de Celulose e Papel é a mais bem sucedida do setor florestal brasileiro. Vale lembrar que, desde o início de suas atividades no Brasil, o segmento teve em vista as exportações e buscou operar em condições de concorrer com os grandes produtores dos países mais desenvolvidos em razão das características desse mercado que sempre foi marcado pela competição internacional.

Frise-se que, no Brasil, o eucalipto, plantado em povoamentos homogêneos, atinge a mais alta taxa de crescimento observada em plantios florestais no mundo, e constitui-se na principal fonte de matériaprima das empresas que atuam no setor. Poucas e grandes empresas lideram o ranking das maiores produtoras de celulose de fibra curta do Brasil (Tabela 5).

Essas empresas que, em 2000, produziram $94,5 \%$ da oferta brasileira de celulose de fibra curta branqueada, responderam também por $67 \%$ de toda a celulose nacional produzida naquele ano (Rodriguez, 2003).

TABELA 5: Maiores produtores de celulose de eucalipto.

TABLE 5: Larger producers greaters of cellulose from eucalyptus.

\begin{tabular}{lcc}
\hline Empresas & Produção de celulose 1999 (t) & Reflorestamento (ha) \\
\hline Aracruz Celulose & 1.262 .536 & 144.229 \\
Celulose Nipo-Brasileira & 783.547 & 110.240 \\
Votorantim Celulose e Papel & 727.009 & 100.000 \\
Bahia Sul Celulose & 578.491 & 67.000 \\
Cia Suzano de Papel e Celulose & 437.052 & 50.000 \\
International Paper do Brasil & 327.785 & 33.000 \\
Klabin Riocell & 300.104 & 56.000 \\
Ripasa Celulose e Papel & 296.443 & 52.000 \\
Jarcel Celulose & 290.381 & 40.000 \\
\hline Total & 5.003 .348 & 652.469 \\
\hline
\end{tabular}

Fonte: Rodriguez (2003) 
Em síntese, as indústrias de celulose apresentam as seguintes características:

- São de grande porte;

- Possuem localização geográfica relativamente descentralizada;

- São em pequeno número de unidades de produção;

- Operam sob economia de escala;

- São de capital intensivo (grande investimento nas fábricas, em geral centenas de milhões de dólares);

- São verticalizadas (as empresas têm capacidade econômica e financeira de estabelecer seus próprios plantios);

- Requerem milhares de metros cúbicos de matéria-prima por dia (toretes de 8 a $30 \mathrm{~cm}$, sem grandes restrições);

- Possuem um alto grau de profissionalização;

- São abertas (voltadas para o mercado externo);

- Possuem ações negociadas em bolsa de valores.

\section{Painéis de madeira reconstituída}

Existe uma gama de produtos produzidos no Brasil que são denominados painéis de madeira reconstituída ou compostos particulados (Figura 3).

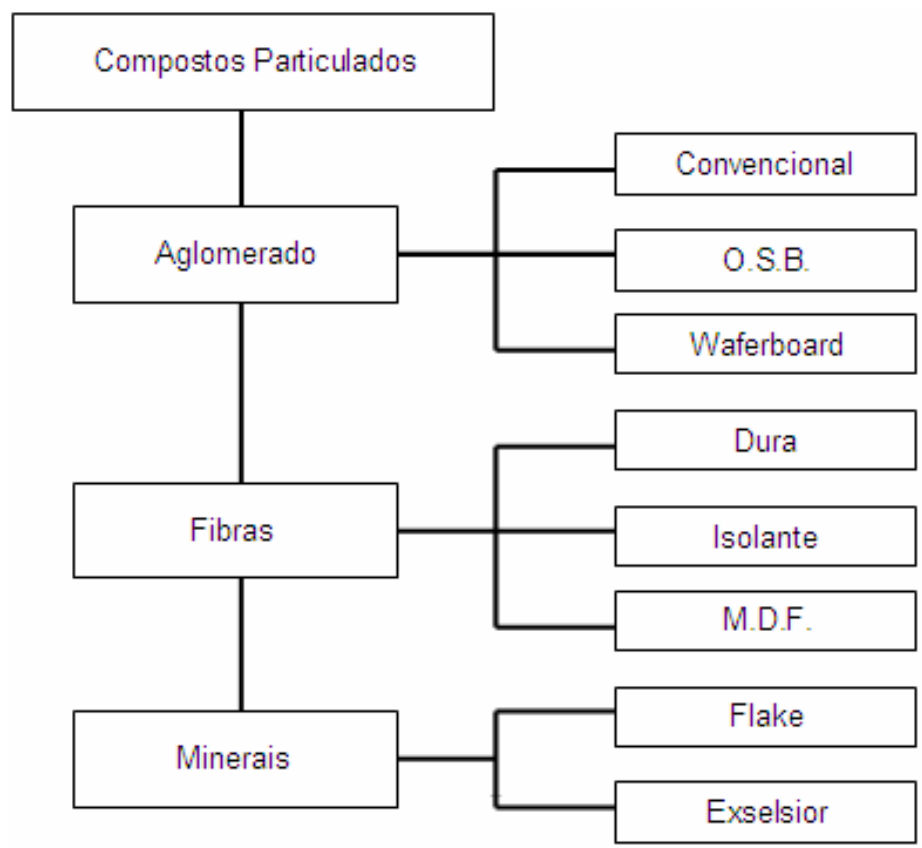

FIGURA 3: Esquema representativo dos compostos particulados (Adaptado de Mendes et al., 2003).

FIGURE 3: Outline of particle composites (Adapted from Mendes et al., 2003).

Os diversos tipos de painéis ou chapas produzidos por essas indústrias são destinadas às fabricas de móveis, construção civil e de outros produtos, as atacadistas e as varejistas e à exportação. São poucas fábricas e relativamente grandes, conforme a Tabela 6.

Na década de 1990, a indústria brasileira de painéis de madeira reconstituída expandiu-se de maneira notável o que pode ser confirmado ao comparar a produção do ano $1994\left(1.312 .686 \mathrm{~m}^{3}\right)$ com a produção do ano $2000\left(2.702 .342 \mathrm{~m}^{3}\right)$. Seguindo a tendência mundial, tal indústria vem modernizando-se rapidamente para garantir competitividade (Mendes et al., 2003).

Geralmente as indústrias de painéis de madeira reconstituída são menores do que as de celulose, mas também possuem capacidade econômica e financeira para a formação de florestas e requerem matéria-prima semelhante à da celulose. 
TABELA 6: Empresas, localização, tipos de produtos e capacidade nominal instalada no ano de 2003. TABLE 6: Companies, localization, types of products and nominal capacity installed in 2003.

\begin{tabular}{|c|c|c|c|c|}
\hline Empresa & Localização & Produto & \multicolumn{2}{|c|}{$\begin{array}{c}\text { Capacidade } \\
\text { instalada/empresa ( } \mathrm{m}^{3} / \text { ano) }\end{array}$} \\
\hline Berneck Aglomerados S.A. & Araucária/PR & Aglomerado & 280.000 & $400.000 *$ \\
\hline Bonet & Santa Cecília/SC & Aglomerado & 42.000 & $52.000 *$ \\
\hline Duratex S.A. & $\begin{array}{l}\text { Gravataí/RS } \\
\text { Itapetininga/SP } \\
\text { Botucatu/SP } \\
\text { Jundiaí/SP } \\
\text { Agudos/SP } \\
\end{array}$ & $\begin{array}{l}\text { Aglomerado } \\
\text { Chapas de fibra } \\
\text { MDF }\end{array}$ & 330.000 & $\begin{array}{l}380.000^{*} \\
370.000 \\
180.000\end{array}$ \\
\hline Eucatex S.A. Ind. e Com. & $\begin{array}{l}\text { Botucatu/SP } \\
\text { Salto/SP }\end{array}$ & $\begin{array}{l}\text { Aglomerado } \\
\text { Chapas de fibra }\end{array}$ & 324.000 & $\begin{array}{l}360.000^{*} \\
230.000\end{array}$ \\
\hline Placas do Paraná S.A. & $\begin{array}{l}\text { Curitiba/PR } \\
\text { Jaguariaíva/PR }\end{array}$ & $\begin{array}{l}\text { Aglomerado } \\
\text { MDF }\end{array}$ & & $\begin{array}{l}300.000 \\
220.000\end{array}$ \\
\hline Masisa & Ponta Grossa/PR & MDF & & 240.000 \\
\hline Satipel industrial S.A. & $\begin{array}{l}\text { Uberaba/MG } \\
\text { Taquari/RS } \\
\end{array}$ & Aglomerado & & 340.000 \\
\hline Seta & Esteio/RS & Aglomerado & & 9.000 \\
\hline Tafisa Brasil S.A. & Piên/PR & $\begin{array}{l}\text { Aglomerado } \\
\text { MDF }\end{array}$ & 145.000 & $\begin{array}{l}204.000 \\
384.000 *\end{array}$ \\
\hline
\end{tabular}

Em que: * = Aumento de produção; Fonte: Mendes et al. (2003).

Em síntese, as indústrias de painéis de madeira reconstituída apresentam as seguintes características:

- São grandes conjuntos.

- Possuem localização geográfica centralizada (regiões Sul e Sudeste).

- São em pequeno número de unidades de produção.

- São de capital intensivo (grande investimento nas fábricas).

- São verticalizadas (as empresas têm capacidade econômica e financeira de estabelecer seus próprios plantios).

- Possuem um alto grau de profissionalização.

- São abertas (voltadas para o mercado externo).

\section{Segmento do Processamento Mecânico}

A indústria do processamento mecânico compreende as serrarias, as produtoras de lâminas para a indústria de compensados, as de lâminas decorativas e as produtoras de PMVA (produtos de maior valor agregado).

\section{Madeira serrada}

A indústria brasileira de serrados teve um crescimento acentuado nas duas últimas décadas.

A indústria brasileira ocupa, em termos de produção, a $9^{\underline{a}}$ posição no ranking internacional de madeira serrada de coníferas. O destaque para a produção brasileira de madeira serrada com base em folhosas é maior. O País ocupa o $2^{0}$ lugar em termos de produção mundial (ABIMCI, 2003a).

Segundo a SBS (2001b), em 2000, a produção brasileira de madeira serrada foi de $23.100 .000 \mathrm{~m}^{3}$, sendo $15.000 .000 \mathrm{~m}^{3}$ provenientes de folhosas e $7.800 .000 \mathrm{~m}^{3}$ de coníferas (Figura 4).

Atualmente, o parque industrial brasileiro voltado à produção de serrados, dispõe de aproximadamente 100.000 unidades. Destas, apenas $1 \%$ possui capacidade de produção média-grande. Praticamente $99 \%$ da força produtiva é oriunda de empresas de pequeno porte, em geral com alto custo operacional (ABIMCI, 2003 b).

As principais características dessa indústria são as seguintes:

- Grande número de pequenas unidades de produção.

- Possuem localização geográfica bastante descentralizada.

- As tecnologias e equipamentos utilizados são nacionais. 
- Demanda de toras na ordem de dezenas de metros cúbicos por dia.

- A valorização do produto é diretamente ligada ao cuidado no manejo da floresta.

- Geralmente remunera atributos de qualidade (diâmetros adequados, boa forma e ausência de defeitos (rachaduras e nós).

- Investimentos baixos;

- São de mão-de-obra intensiva; (grande geração de empregos diretos em relação aos investimentos um emprego direto a cada $\mathrm{R} \$ 20.000$ em média investidos em equipamentos e instalações) (ABIMCI, 2003 c).

- Alimenta indústrias secundárias com características sócio-econômicas semelhantes (relativamente pequenas, baixos investimentos, alta geração de empregos).

- Baixo grau de verticalização (as madeireiras, em geral, não têm capacidade econômica financeira para investir em florestas próprias).

- Possuem um baixo grau de profissionalização.

- São abertas (possuem um considerável volume de exportação, mas não se encontram no mesmo estágio de desenvolvimento da Cadeia Produtiva da Madeira industrial).

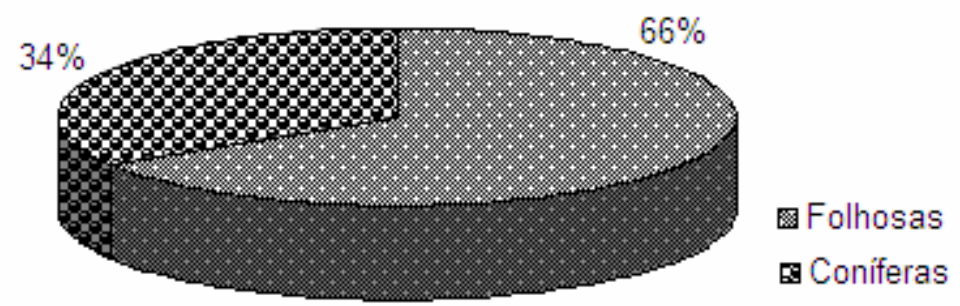

FIGURA 4: Produção de madeira serrada no Brasil no ano de 2000.

FIGURES 4: Sawed wooden production in Brazil in 2000.

\section{Compostos laminados}

Diferentes produtos são denominados como compostos laminados (Figura 5).

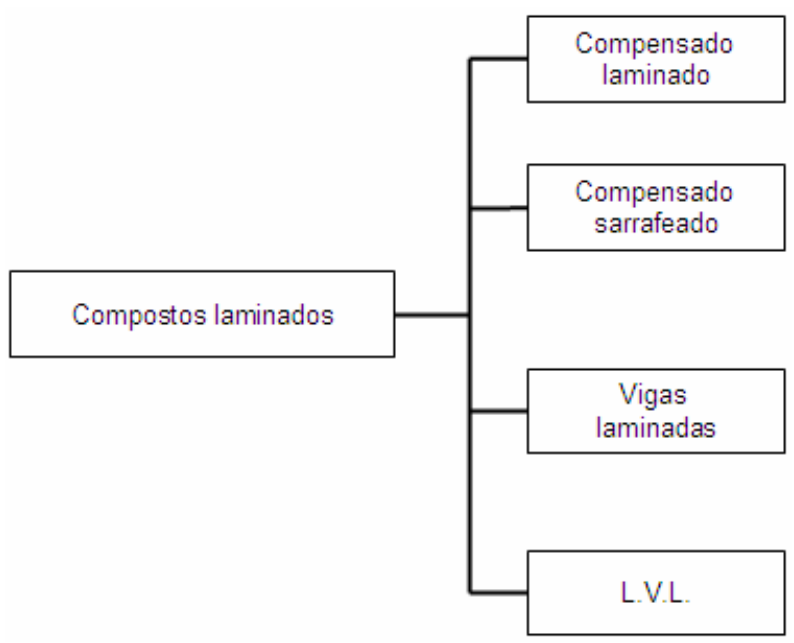

FIGURA 5: Esquema representativo dos compostos laminados (Adaptado de Mendes et al., 2003).

FIGURE 5: Outline of veneer composites (Adapted from Mendes et al., 2003).

A produção do compensado se iniciou no Brasil na década de 40 , embora só se tenha atingido níveis de produção significativos no ano de 1970.

Vale ressaltar que a produção de vigas laminadas e a de LVL (Lâmina de Madeira Serrada) demanda um alto investimento, mão-de-obra especializada, etc., e que a produção brasileira é insignificante, sendo assim excluída da análise a seguir. 
Colocado como o $6^{-}$maior produtor mundial de compensados, o Brasil atualmente responde pelo volume de 2,6 milhões de $\mathrm{m}^{3}$, o que representa, em termos relativos, $4,5 \%$ da produção total mundial, atualmente no patamar de 55,5 milhões de $\mathrm{m}^{3}$ (ABIMCI, 2003a). Grande parte do volume produzido é direcionado à exportação. Em 2002, o País exportou cerca de 1,8 milhão de $\mathrm{m}^{3}$, o que representou $8,7 \%$ do volume total comercializado internacionalmente $\left(20,7\right.$ milhões de $\left.\mathrm{m}^{3}\right)$.

No que diz respeito à matéria-prima utilizada, estima-se que $60 \%$ do compensado nacional sejam produzidos com matéria-prima tropical, enquanto os outros $40 \%$ com madeira de florestas plantadas nas regiões Sul e Sudeste (particularmente o Pinus), incluindo o tipo "combi" que possui a face em madeira tropical e o miolo em madeira de Pinus (ABIMCI, 2000).

Entretanto, apesar de sua importância para o País e dos avanços verificados ao longo do tempo, observa-se que o segmento é bastante fragmentado.

Os inexpressivos investimentos tecnológicos, realizados recentemente nas indústrias de compensado, bem como a deficitária estrutura de produção e os elevados custos com matéria-prima (nativas da região Norte) caracterizam-se como fatores limitantes ao desenvolvimento da produção desse tipo de painel no Brasil (ABIMCI, 2000).

As principais características dessa indústria são as seguintes:

- São em grande número de pequenas unidades de produção (estruturação tipicamente familiar).

- Possuem localização geográfica relativamente descentralizada.

- Apresentam geralmente baixos investimentos em tecnologia (o que resulta em uma deficitária estrutura de produção).

- Ofertam um produto bastante heterogêneo.

- Investimentos baixos.

- São intensivas em mão-de-obra.

- Baixo grau de verticalização (em geral não tem capacidade econômico financeira para investir em florestas próprias).

- Possuem um baixo grau de profissionalização.

- São abertas (possuem um considerável volume de exportação, mas não se encontram no mesmo estágio de desenvolvimento da Cadeia Produtiva da Madeira industrial).

\section{Produtos de maior valor agregado}

De acordo com ABIMCI (2000), as empresas produtoras de serrados, (em particular as de grande e médio porte) apresentam tendência de agregar valor ao produto serrado, tendo esse processo iniciado a partir do final dos anos 80 , com vistas sobretudo ao mercado externo e ao segmento moveleiro nacional.

Dentre os principais Produtos de Maior Valor Agregado (PMVA) produzidos no Brasil, mas com foco no mercado externo, podem ser citados os blocks, blanks, molduras, fence, pisos, janelas e outros, enquanto os voltados ao setor moveleiro são especialmente os pré-cortados, componentes estruturais, EGP (Edge Guide Panel) e outros.

Para fabricação do PMVA, utilizam-se em especial o Pinus e algumas espécies nativas, como ipê, imbuia, jatobá e outras, porém observa-se um crescimento da participação do eucalipto, em virtude de seu potencial, da tendência de esgotamento das espécies nativas e mesmo de restrições para a comercialização de produtos oriundos de florestas nativas, sobretudo por parte do mercado externo.

As principais características dessa indústria são as seguintes:

- São em menor número e geralmente são grandes unidades de produção.

- Possuem localização geográfica relativamente descentralizada.

- Apresentam investimentos médios em tecnologia.

- Baixo grau de verticalização (em geral não têm capacidade econômico financeira para investir em florestas próprias).

- São abertas (possuem um considerável volume de exportação, mas não se encontram no mesmo estágio de desenvolvimento da Cadeia Produtiva da Madeira Industrial). 


\section{Segmento de madeira para energia: carvão vegetal e lenha}

A madeira é provavelmente o combustível mais antigo, e conhecido do homem, já que o início de sua utilização está diretamente vinculado com o descobrimento do fogo. Nos dias atuais, a utilização da madeira como combustível está normalmente relacionada com os produtos secundários obtidos desta como, por exemplo, o carvão vegetal e a lenha.

No Brasil, a madeira é usada amplamente como fonte de energia, sendo o País um dos maiores produtores de carvão vegetal e de lenha do mundo. Quanto às exportações, verifica-se um baixo percentual em relação a produção, em 2001 a exportação foi de $9.338 \mathrm{t}$, ou seja, $0,45 \%$ da produção (ABRACAVE, 2003).

Apesar da redução do consumo nos últimos anos, o carvão vegetal ainda possui uma posição de grande importância na economia brasileira, em especial para Minas Gerais, principal estado produtor e consumidor (Tabela 7), onde ocupa posição de destaque no setor siderúrgico, no qual contribui para a produção de ferro-gusa, aço e ferro-liga.

Além da indústria siderúrgica, o carvão vegetal também participa como substituto do óleo combustível nas caldeiras e nos fornos de combustão da indústria de cimento e de materiais primários.

TABELA 7: Consumo de carvão vegetal, por estado, no ano de 2000.

TABLE 7: Consumption of charcoal, by state, in 2000.

\begin{tabular}{lc}
\hline Estado & Consumo (mdc) \\
\hline Minas Gerais & 17.120 .000 \\
São Paulo & 760.000 \\
Bahia & 470.000 \\
Rio de Janeiro & 365.000 \\
Espírito Santo & 1.100 .000 \\
Mato Grosso do Sul & 315.000 \\
Outros & 6.090 .000 \\
\hline Total & 26.220 .000 \\
\hline
\end{tabular}

Fonte: ABRACAVE (2003).

No setor industrial, o ferro-gusa, aço e ferro-ligas são os principais consumidores do carvão vegetal (quase 85\%), que funciona como redutor e energético ao mesmo tempo. O setor residencial consome cerca de $9 \%$ seguido pelo setor comercial com 1,5\%, representado por pizzarias, padarias e churrascarias (USP, 2003).

Segundo Leão (2000), o segmento de carvão vegetal destinado à siderurgia no Brasil é representado por 110 empresas (nove usinas integradas a carvão vegetal, 82 usinas de ferro-gusa e 19 de ferro-ligas), que alcançaram, em 1996, um faturamento de 4,3 bilhões de dólares.

Ainda segundo o autor, o consumo de carvão vegetal alcançou em 1997 cerca de 23,6 milhões de metros cúbicos apresentando decréscimo em relação a 1995, quando atingiu mais de 31 milhões de metros cúbicos. Nos últimos tempos, a participação da madeira proveniente dos reflorestamentos nesse segmento vem aumentando em detrimento da exploração das matas nativas e, hoje, situa-se em torno de $75 \%$.

No que diz respeito à origem da matéria-prima da produção de carvão vegetal, verifica-se uma tendência de substituição da madeira oriunda de florestas nativas pelas de reflorestamento.

Apesar de sua importância no contexto industrial brasileiro, verifica-se que o aumento da eficiência nos elos da cadeia produtiva do carvão vegetal ainda se encontra bastante incipiente no País.

Parte significativa do carvão vegetal é obtida com o emprego de técnicas bastante rudimentares, mão-de-obra pouco qualificada e pequena alocação de recursos. No Brasil, a tecnologia adotada por grande parte dos produtores de carvão vegetal ainda é carente de novos processos. Ainda se produz de forma rudimentar em fornos de argila (tijolos) cuja construção exige um baixo nível de investimento. Não-raras vezes, a atividade de carvoejamento tem sido associada com condições desumanas de trabalho. 
O transporte desse carvão, geralmente produzido à beira ou no interior das florestas, até as unidades consumidoras (siderúrgicas) se faz através de caminhões comuns, algumas vezes equipados com "gaiolas", não havendo, assim, investimento em equipamentos específicos para essa finalidade. Seu mercado é considerado desorganizado.

Neste contexto, vale destacar a existência do esforço de diferentes atores sociais (empresas, universidades, órgãos públicos) tendo em vista modificar esta realidade, e no seu lugar surgir, uma indústria limpa, sustentável e renovável, geradora de empregos dignos e de divisas para o país.

As principais características dessa indústria são as seguintes:

- Poucas empresas grandes e um significativo percentual de pequenas e médias unidades de produção.

- Possuem localização geográfica bastante descentralizada.

- São voltadas para o mercado interno (fechadas).

- Apresenta poucas restrições quanto à matéria prima (em geral valoriza madeira mais densa).

- Não são tecnifícadas.

- Investimentos muito baixos.

- São de mão-de-obra intensiva; (grande geração de empregos diretos em relação aos investimentos).

- Baixo grau de verticalização (as produtoras de ferro guza em geral não têm interesse em investir em florestas próprias).

- Possuem um baixíssimo grau de profissionalização.

\section{CONSIDERAÇÕES GERAIS}

Ao se caracterizar o setor florestal, contrastado-o com os demais setores da economia, pode-se afirmar que a gestão do negócio florestal no Brasil é diferenciada da gestão da maioria de outros negócios no País. Isso se dá com base no complexo contexto macroambiental, extremamente coercitivo, no qual as empresas florestais estão situadas.

Vale lembrar que o ambiente organizacional funciona como um campo dinâmico de forças que interagem entre si provocando mudanças e influências, diretas e indiretas, sobre as organizações. É uma fonte de recursos e oportunidades da qual a organização extrai os insumos necessários ao seu funcionamento e subsistência, mas é também uma fonte de restrições, limitações, coações, problemas, ameaças e contingências para a sua sobrevivência e desenvolvimento.

No atual cenário socioeconômico, político e ambiental brasileiro, muitos são os desafios a serem enfrentados pelas empresas florestais. A estrutura organizacional do setor florestal é de gestão descentralizada, e voltada, prioritariamente, à questão do meio ambiente. A produção florestal é entendida como parte da gestão ambiental.

Tais fatos, seguramente diminuem a competitividade das empresas do setor. Assim, a potencialidade do recurso florestal brasileiro não tem sido utilizada de maneira a garantir respostas sociais e econômicas satisfatórias. Vale ressaltar que, embora tais respostas possuam expressividade, estão, com certeza, muito aquém do potencial existente, podendo crescer significativamente.

Nesse contexto, os representantes dos diferentes segmentos do setor florestal reivindicam um tratamento adequado, compatível com as peculiaridades inerentes as atividades florestais. Frise-se que, em momento algum, se preconiza o paternalismo e, sim, que se criem condições necessárias à coexistência das empresas brasileiras no contexto da competitividade que atualmente se vivencia.

É de extrema importância, para o Brasil, trilhar o caminho da racionalidade e pelo diálogo dos diferentes atores sociais articular as mudanças necessárias, para se definir as formas de uso do recurso florestal pela possibilidade técnica e científica, direcionado à geração de bens e serviços, pois só assim o setor privado poderia adotar um modelo de gestão adequado, tendo em vista o mercado global. 


\section{REFERÊNCIAS BIBLIOGRÁFICAS}

ABIMCI - ASSOCIAÇÃO BRASILEIRA DA INDÚSTRIA DE MADEIRA PROCESSADA MECANICAMENTE. Relatório setorial. 2000. 54 p.

ABIMCI - ASSOCIAÇÃO BRASILEIRA DA INDÚSTRIA DE MADEIRA PROCESSADA E INDÚSTRIAL Dados setoriais. Disponível em: <http://www.abimci.com.br/port/03Dados/03FrameDados.htmll. Acesso em: 15 setembro 2003 a.

ABIMCI - ASSOCIAÇÃO BRASILEIRA DA INDÚSTRIA DE MADEIRA PROCESSADA E INDÚSTRIAL O setor de madeira sólida no Brasil \& contribuições à política industrial. Disponível em: $<$ http://www.abimci.com.br/port/06Docs/pdf/Pollnd.pdf> . Acesso em: 15 setembro 2003 b.

ABIMCI - ASSOCIAÇÃO BRASILEIRA DA INDÚSTRIA DE MADEIRA PROCESSADA E INDÚSTRIAL. Madeira processada mecanicamente: estudo setorial - 2001 Disponível em: $<$ http://www.abimci.com.br/port/03Dados/0301EstSet2001/pdf/ABIMCI\%20EstSet2001p.pdf $>$. Acesso em: 15 setembro $2003 \mathrm{c}$.

ABIPA - ASSOCIAÇÃO BRASILEIRA DA INDÚSTRIA DE PAINÉIS DE MADEIRA. Estatísticas. Disponível em: $<$ http://www.sbs.org.br/estatisticas.htm>. Acesso em: 15 setembro 2003.

ABRACAVE - ASSOCIAÇÃO BRASILEIRA DE FLORESTAS RENOVÁVEIS. Anuário. Disponível em: < http://www.abracave.com.br/index_princ.htm>. Acesso em: 15 setembro 2003.

ASSIS, J. B. Base florestal de Minas Gerais. In: SEMINÁRIO DE PRODUTOS SÓLIDOS DE MADEIRA DE EUCALIPTO, 2, 2003, Belo Horizonte. Anais... Viçosa : SIF, 2003. 210 p. p. 32-42.

BRACELPA - ASSOCIAÇÃO BRASILEIRA DE PAPEL E CELULOSE. Características gerais do setor números do setor celulose - papel - 2002. Disponível em: <http://www.bracelpa.org.br/prog_investimento/Prog0312.pdf > Acesso em: 15 setembro 2003.

BRASIL. Primeiro relatório nacional para a convenção sobre diversidade biológica. Disponível em: $<$ http://www.mma.gov.br/biodiversidade/doc/cap2a.pdf >. Acesso em: 15 setembro 2003.

FAO - FOOD AND AGRICULTURE ORGANIZATION OF THE UNITED NATIONS. FRA 2000 : termos e definições. Roma : Departamento de Florestas Organização das Nações Unidas para a Agricultura e a Alimentação, 1998. Disponível em: <www.fao.org/forestry/fo/fra/docs/FRA_Wplport.PDF> Acesso em: 21 maio 2002.

GARLIP, R. C. Competências e competitividade do setor florestal. Disponível em: $<$ http://www.sbs.org.br/secure/palestra-download.php> Acesso em: 17 julho 2001

HUMMEL, A. C.; MINETTE L. J. Aspectos do setor florestal do estado da Amazônia In: CONGRESSO FLORESTAL BRASILEIRO, 6. 1990, Campos do Jordão. Anais... São Paulo: SBS, 1990. p. 157-165.

IPEF - INSTITUTO DE PESQUISAS E ESTUDOS FLORESTAIS. Ciência e tecnologia no setor florestal brasileiro: diagnóstico, prioridades e modelo de financiamento. Disponível em: $<$ http://www.ipef.br/mct/MCT_02.htm> Acesso em: 16 setembro 2003.

LEÃO, R. M. A floresta e o homem. São Paulo: Edusp, 2000. 447 p.

MENDES L. M.; ALBUQUERQUE, C.E.C.; IWAKIRI, S. A indústria brasileira de painéis de madeira Revista da Madeira, Curitiba, ano 13, n. 75, p.12-20, 2003.

POLZL, W.B.; SANTOS A. J.; TIMOFEICZK, R. J.; POLZL, P. K. Cadeia produtiva do processamento mecânico da madeira: Segmento da madeira serrada no estado do Paraná. Disponível em: < www.tropicalcongress.com.br/portugues/anais.html> Acesso em: 16 setembro 2003.

REZENDE, J. L. P.; LIMA V. B. J.; SILVA, M. L. O setor florestal brasileiro. Informe Agropecuário, Belo Horizonte, n. 185, p. 7-14, 1996.

RODRIGUEZ L.C. E. Ordenamento sustentável dos plantios de eucaliptos manejados para a produção de celulose no Brasil Disponível em: <http://jatoba.esalq.usp.br/ lcer/simposio/trabluizcarlos.doc > Acesso em: 15 setembro 2003.

SBS - SOCIEDADE BRASILEIRA DE SILVICULTURA. Rede SBS dia a dia 28/08/2003. [mensagem pessoal]. Mensagem recebida por <rosamaria@homenet.com.br> em 28 agosto 2003 a.

SBS - SOCIEDADE BRASILEIRA DE SILVICULTURA. Estatísticas. Disponível em: 
$<$ http://www.sbs.org.br/estatisticas.htm> Acesso em: 15 setembro 2003 b.

SILVA, J. C. Perspectivas do setor florestal brasileiro. Revista da Madeira, Curitiba, ano 13, n. 75, p. 04-06, 2003.

USP - UNIVERSIDADE ESTADUAL DE SÃO PAULO. Banco de dados de biomassa no Brasil. Disponível em: $<$ http://infoener.iee.usp.br/scripts/biomassa/br_carvao.asp> Acesso em: 15 setembro 2003.

VALVERDE, S. R. A contribuição do setor florestal para o desenvolvimento sócio-econômico: uma aplicação de modelos de equilíbrio multissetoriais. 2000. 105p. Tese (Doutorado em Ciência Florestal) - Universidade Federal de Viçosa, Viçosa/MG, 2000.

VALVERDE, S. R.; CARVALHO, R. M. M.; SOARES, T. S.; OLIVEIRA, P. R. S. Evolução da participação do setor florestal na economia brasileira. In: CONGRESSO FLORESTAL BRASILEIRO, 8. 2003, São Paulo. Anais... São Paulo: SBS/SBEF, 2003. 2 CD-ROM. 